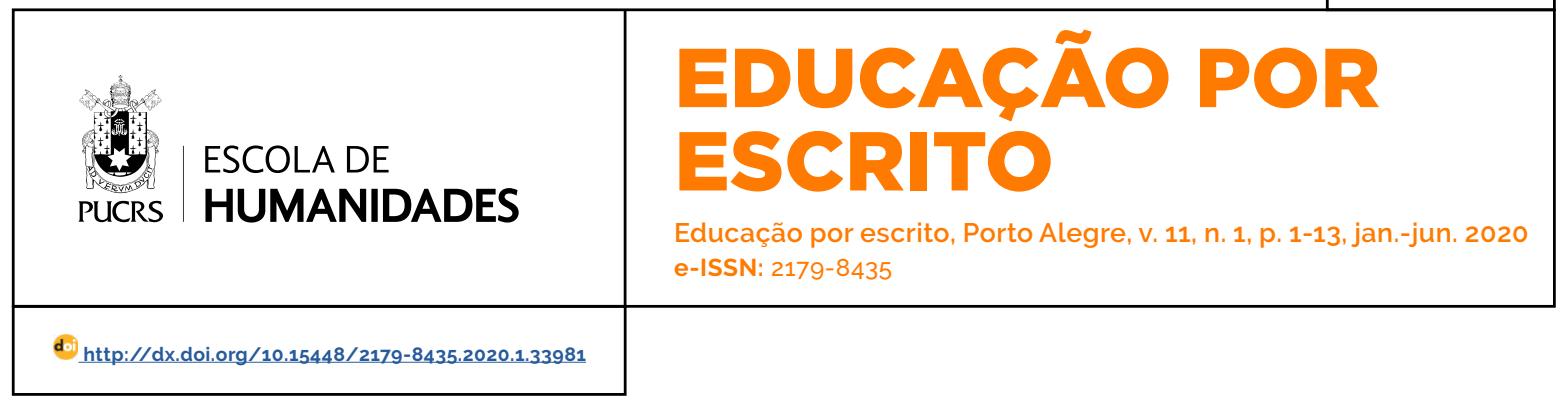

SEÇÃO ARTIGOS

\title{
Práticas de leitura de professoras alfabetizadoras: como se ensina a ler?
}

\author{
Reading practices of literacy teachers: how do you teach reading?
}

\section{Luiara Maria da Cruz $^{1}$ \\ orcid.org/0000-0001-7154-2454 \\ luiaracruz@hotmail.com}

\section{Vivianny Bessão de}

Assis $^{1}$

orcid.org/0000-0003-3146-0627

viviannybessao@gmail.com

Recebido em: 24 abr. 2019 Aprovado em: 8 jan. 2020. Publicado em: 27 jul. 2020
Resumo: Esta pesquisa buscou conhecer como tem sido as práticas de professoras alfabetizadoras no ensino da leitura seus alunos, em turmas do $2^{\circ}$. ano do ensino fundamental de uma escola pública na região sul do estado de Mato Grosso do Sul (MS) que vem obtendo os maiores índices no Índice de Desenvolvimento da Educação Básica no município e nas regiões vizinhas, alcançando 7,3 em 2015. e 6.9 em 2017. O eixo metodológico da pesquisa centra-se na abordagem qualitativa e descritiva, a partir de entrevistas e questionário semiestruturado aplicado a três professoras e uma coordenadora da escola mencionada. Os resultados apontam que a escola vem obtendo sucesso nos índices de alfabetização por diversos fatores: as professoras sentem-se confiantes e valorizadas na escola; a figura da coordenadora é multifacetada, atuando como promotora da leitura literária entre os alunos e como articuladora das práticas conjuntas das professoras; a escola investe em simulados e provas semelhantes às cobradas pelo Ministério da Educação (MEC); há propostas de "leitura para casa" desenvolvidas pela coordenação pedagógica. Os resultados da pesquisa indicam que o sucesso das práticas de leitura e escrita não estão relacionadas à escolha de um método de ensino ou a uma proposta metodológica definida pela escola, mas por um trabalho que envolve parceria e gestão pedagógica.

Palavras-chave: Aprendizagem da leitura. Ciclo de alfabetização. Prática de professores.

Abstract: This research sought to know how has been the practices of literacy teachers in reading teaching with their students, in classes of the 2nd. year of elementary school in a public school in the southern region of the state of Mato Grosso do Sul (MS), which has been obtaining the highest indexes in Ideb in the municipality and neighboring regions, reaching 7.3 in 2015 and 6.9 in 2017. The methodological focus of the research is centered in the qualitative and descriptive approach based on interviews and semi-structured questionnaire applied to three teachers and a coordinator of the mentioned school. The results indicate that the school has been successful in the literacy indexes for several factors: the teachers feel confident and valued in the school; the figure of the coordinator is multifaceted, acting as promoter of the literary reading among the students and as articulator of the joint practices of the teachers; the school invests in simulations and tests similar to those collected by the MEC; there are proposals for "home reading" developed by pedagogical coordination. The results of the research indicate that the success of reading and writing practices are not related to the choice of a teaching method or methodological proposal defined by the school, but by a work involving partnership and pedagogical management.

Keywords: Reading learning. Literacy cycle. Practice of literacy teachers.

\section{Situando a pesquisa: como as crianças aprendem a ler?}

O processo de alfabetização é uma etapa de grande importância na vida do aluno, já que será a partir desse aprendizado que as palavras 
farão sentido e contribuirão para a sua trajetória escolar e também para a sua formação como ser humano. Para que essa aprendizagem seja de fato válida, é necessário que o processo de alfabetização seja significativo, despertando no aluno a vontade de aprender, pois a leitura é fundamental para a aprendizagem da criança.

São nos primeiros anos escolares que a criança passa a ter contato com textos de forma geral, podendo manuseá-los e lê-los do seu próprio jeito, para os diferentes fins. A leitura oportuniza ao aluno apropriar-se dos mais variados conhecimentos. Desse modo, o processo de alfabetização se caracteriza como aquele em que o aluno compreende a relação entre a escrita e o seu significado, sobre o sistema de representação da escrita e sobre os segmentos sonoros da fala.

De acordo com Monteiro e Baptista (2009, p. 19), a "[...] alfabetização se refere ao processo por meio do qual o sujeito domina o código e as habilidades de utilizá-lo para ler e escrever". Nesse sentido, aprender a ler e a escrever alfabeticamente relaciona-se com a ação de escrever com autonomia aquilo que o aluno compreende. Nesses termos, Bruneri (2013, p. 4) afirma que a alfabetização pode ser entendida "[...] como um sistema mais amplo, ou seja, como um processo de compreensão e expressão de significados morfológicos, sintáticos e semânticos da língua escrita", que "[...] alfabetizar é fazer com que o educando compreenda as convenções do código alfabético, decifrando as estruturas arbitrárias da escrita, através do desenvolvimento de competências e habilidades de análise estrutural das palavras como reflexão metalinguistica (BRUNERI, 2013, p. 4)

Para alcançar uma concepção de alfabetização dessa natureza que propicie "reflexão metalinguística", conforme aponta Bruneri (2013, p. 4), é necessário pautar o trabalho com a língua no "[...] desenvolvimento de comportamentos e habilidades de uso competente da leitura e da escrita em práticas sociais [...]" ou seja, nas práticas do letramento (SOARES, 2004, p. 91).
Pode-se dizer ainda que o letramento desenvolve a capacidade de interpretar e utilizar linguagens diferenciadas com os diversos tipos de textos.

Muitas crianças ao ingressarem nos anos iniciais do ensino fundamental já tiveram a oportunidade de ter contato não só com livros, mas também com os diversos tipos de gêneros textuais existentes em seu cotidiano por meio de propagandas, receitas, bilhetes, recados e outros. Na concepção de Jesus (2006, p. 13) o ato da leitura,

[...] acontece em todos os lugares. Lê-se em casa, mas lê-se também nos bancos das praças, nas ruas, no ônibus, no metrô, nos aviões etc. E além de textos nas mãos, o indivíduo recebe outras mensagens escritas: placas, avisos luminosos, outdoors (JESUS, 2006, p. 13).

O foco desta pesquisa foi investigar à respeito da alfabetização nos anos iniciais do ensino fundamental, especificamente, sobre a aprendizagem da leitura em crianças dos alunos que encontram-se no $1^{\circ}$. ciclo de alfabetização². O interesse por este estudo decorreu das atividades desenvolvidas no Projeto de Extensão Intitulado "Ações colaborativas entre universidade e escola no municipio de Naviraí: apoio pedagógico em alfabetização, letramento e matemática", desenvolvido pelo curso de Pedagogia da Universidade de Mato Grosso do Sul (UFMS), campus de Naviraí - MS, que atendeu, em média, 50 crianças de uma escola deste municipio, as quais apresentavam dificuldades na aprendizagem da leitura e da escrita.

A partir dessa experiência, calcada em um trabalho pedagógico com base na teoria construtivista e no letramento, notou-se considerável sucesso na aprendizagem inicial da leitura e escrita desses alunos, atingindo o percentual de 58\% de avanço no ano de 2017 e $71,4 \%$ no ano de 2018 . Todos esses resultados e discussões teóricas eram discutidos na linha "Leitura, escrita e literatura", do Grupo de Estudos e Pesquisa em "Prática Educacional" (GEPPETE)e, a partir do contato com esses alunos, um grande interesse emergiu aos membro do grupo visando

\footnotetext{
2 De acordo com o Ministério da Educação (MEC) o ciclo de alfabetização compreende os três anos iniciais do ensino fundamental de nove anos (BRASIL, 2010).
} 
compreender como os professores das demais escolas do município ensinavam a leitura no processo de alfabetização.

O requisito adotado foi verificar o número de escolas existentes no município e acompanhar aquela que tivesse maior pontuação no Índice de Desenvolvimento da Educação Básica (Ideb). O municipio de Naviraí conta com seis escolas municipais e seis estaduais e os índices do Ideb estão entre 5,0 e 7,3 na classificação geral. De acordo com pesquisas realizadas foi possivel perceber que a escola estadual Juracy Alves Cardoso alcançou o maior índice na cidade com a nota de 7,3 em 2015. Este foi um indice relativamente alto considerando a média nacional que é de 5,8 e a média estadual de 5,4 no penúltimo Ideb. Atualmente a escola estudada sofreu uma pequena decaída no índice, entretanto, a média alcançada foi de 6,9em 2017. sendo ainda a maior da cidade. ${ }^{3}$

Para alcançar os objetivos da pesquisa buscou-se conhecer a opinião dos professores e da coordenadora, que exerce a função de bibliotecária da escola, a fim de adquirir mais informações a respeito das práticas de leitura desenvolvidas no ambiente escolar. Logo, o presente estudo buscou compreender como os professores utilizavam os materiais de leitura no $2^{\circ}$ ano do ensino fundamental e os motivos pelos quais essas práticas estavam conseguindo alcançar altos índices no Ideb? Quais tipos de livros e/ou matérias voltados para o público infantil existem no acervo da escola e do professor? Como eram desenvolvidas as práticas de leitura com as crianças?

Para o desenvolvimento desta investigação foi realizada uma pesquisa de campo de natureza qualitativa, por meio de entrevistas semiestruturas com três professoras atuantes no $2^{\circ}$. ano do ensino fundamental da escola mencionada e com uma coordenadora da escola a fim de conhecer como têm sido desenvolvidas as práticas de leitura pelos professores em sala de aula.

Dessa forma, o presente estudo encontra-se assim organizado: inicialmente apresenta-se esta introdução fundamentada em autores para melhor entender a temática sobre a aquisição da aprendizagem da leitura; em seguida descrevese a metodologia utilizada para a realizar a investigação, com explicações sobre o tipo de pesquisa, o instrumento utilizado para a coleta de dados e participantes da pesquisa de campo; na sequência são apresentados os resultados e discussão fundamentadas em autores que investigam sobre as temáticas da leitura e das bibliotecas escolares; por fim são apresentadas as considerações finais e referências utilizadas para a elaboração deste trabalho de pesquisa.

\section{Como o professor pode ensiná-las a ler?}

Teberosky e Colomer (2002, p. 2) afirmam que ler consiste "[...] em processar as informações visuais de um texto e as informações não-visuais que são os conhecimentos do leitor". Ao adquirir essas informações o leitor passa a formular hipóteses e no desenrolar da leitura constata se a informação que estava no texto é verdadeira ou não. Para Freire (2001),

\begin{abstract}
[l]er é uma operação inteligente, difícil, exigente, mas gratificante. Ninguém lê ou estuda autenticamente se não assume, diante do texto ou do objeto da curiosidade a forma crítica de ser ou de estar sendo sujeito da curiosidade. sujeito da leitura, sujeito do processo de conhecer em que se acha. Ler é procurar buscar criar a compreensão do lido; daí, entre outros pontos fundamentais, a importância do ensino correto da leitura e da escrita. É que ensinar a ler é engajar-se numa experiência criativa em torno da compreensão. [...] e da comunicação (FREIRE, 2001, p. 3, grifo do autor).
\end{abstract}

Nessa perspectiva "[...] a lingua escrita seria, em suma, o meio mais eficiente para que um indivíduo chegue a dominar as máximas potencialidades de abstração da linguagem, independentemente de os discursos construidos por ele serem, ao final, orais ou escritos" (TEBEROSKY; COLOMER, 2002, p. 1). Para Carvalho e Mendonça (2006, p. 21), a leitura pode ser entendida como o processo de decodificação da escrita até a compreensão do texto. A leitura não é desenvolvida

3 Dados retirados do site do IDEB, disponivel em: http://ideb.inep.gov.br/resultado. Acesso em: 2 nov. 2018. 
automaticamente pelo aluno, ela precisa ser exercitada e estimulada constantemente pelo professor quando ele.

a) lê em voz alta e comenta ou discute com eles os conteúdos e usos dos textos lidos; b) proporciona a eles familiaridade com gêneros textuais diversos (histórias, poemas, trovas, canções, parlendas, listas, agendas, propagandas, noticias, cartazes, receitas culinárias, instruções de jogos, regulamentos etc.), lendo para eles em voz alta ou pedindo-lhes leitura autônoma; c) aborda as caracteristicas gerais desses gêneros [...]; e, d) instiga os alunos a prestarem atenção e explicarem os "não ditos" do texto, a descobrirem e explicarem os porquês, a explicitarem as relações entre o texto e seu título (CARVALHO; MENDONÇA, 2006, p. 21)

Somente um trabalho calcado nas práticas de leitura poderá fazer com que os alunos alcancem alguns objetivos como: conseguir compreender um texto, "[...] ser capaz de dizer quem fez o quê, quando, como, onde e por quê" (CARVALHO; MENDONÇA, 2006, p. 21), saber interpretar, tornarse independente para ler e adquirir mobilidade diante de uma sociedade grafocêntrica.

No contexto da aprendizagem da leitura e escrita "[...] o professor é o protagonista ativo da aprendizagem de seus alunos. Em primeiro lugar, é quem decide o que é que deve ser ensinado, os conteúdos, os materiais, a organização do trabalho e da atividade, a avaliação, etc" (MARUNY, 2000, p. 92). Ao dizer isso, Maruny (2000, p. 92) enfatiza a ideia de que "[...] a tarefa do professor, tal como se coloca nas propostas educativas, requer não apenas aplicar certas fórmulas preestabelecidas, como também o exercicio profissional competente, que inclui autonomia, capacidade de decisão e criatividade".

É possivel concluir que a função primordial da escola é "[...] ensinar a ler, e cabe a ela proporcionar situações em que haja contato entre o aluno e a leitura para que ele possa explorar todas as informações que julgar importantes" (RAUEN, 2008, p. 2). No ciclo de alfabetização, o 2. Ano do ensino fundamental visa ...] aprofundar e consolidar alguns conhecimentos e habilidades já introduzidas no primeiro ano: o domínio de correspondências som-grafia; o reconhecimento e o uso de diferentes tipos de letra; a utilização do espaço em branco para separar as palavras dos textos (SEAL; SILVA, 2012, p. 10).
Com base nessas reflexões sobre a prática de leitura diversificada e cientes das exigências curriculares para $01^{\circ}$. ciclo de alfabetização, fomos a campo investigar como a escola selecionada vem alcançando alta taxa de sucesso na alfabetização.

\section{Procedimentos metodológicos}

A pesquisa de campo visou compreender a percepção das relações estabelecidas entre os sujeitos e o ambiente ao seu redor, conhecer seus posicionamentos e a realidade em que a escola se encontra a fim de compreender o trabalho desenvolvido. Decidimos, portanto, por uma pesquisa de natureza qualitativa-descritiva que, de acordo com Ribeiro (2008, p. 4-5), caracteriza-se pela

\begin{abstract}
[...] tentativa de uma compreensão detalhada dos significados e caracteristicas situacionais apresentadas pela realidade em investigação, em lugar da produção meramente quantitativa de características e comportamentos. [...] se desenvolve numa situação natural, é rico em dados descritivos, obtidos no contato direto do pesquisador com a situação estudada, enfatiza mais o processo do que o produto, se preocupa em retratar a perspectiva dos participantes, tem um plano aberto e flexivel e focaliza a realidade de forma complexa e contextualizada (RIBEIRO, 2008, p. 4-5).
\end{abstract}

Assim, a pesquisa qualitativa visa alcançar a qualidade do material coletado, não sendo necessário um número elevado de participantes que farão suas contribuições com o tema abordado. Por isso, no primeiro momento, fizemos uma visita à instituição de ensino com o intuito de conhecer o ambiente escolar e verificar a possibilidade de desenvolver a pesquisa. Na visita seguinte foi possivel selecionar os quatro sujeitos da pesquisa: uma bibliotecária e três professoras que atuavam no 2 . $^{\circ}$ ano do ensino fundamental.

Utilizamos o recurso da entrevista que se caracteriza por uma técnica para a coleta de dados a fim de obter um objetivo definido em uma discussão orientada por meio de perguntas que levaram as entrevistadas a exporem suas opiniões sobre o tema definido (ROSA; ARNOLDI, 2017). Também foi utilizado o questionário com uma das professoras escolhidas, pois não foi possivel realizar a entrevista, uma vez que ela se encontrava em sala de aula e não poderia se 
ausentar por um espaço de tempo maior.

No questionário entregue a professora constavam informações básicas como idade, a sua formação, qual o periodo em que ela lecionava e quantos anos está na escola estudada. Em seguida, haviam seis perguntas sobre o motivo que a instituição de ensino atingiu o maior índice no Ideb na região; quais são as ações ministradas por ela em sala de aula; quais as práticas contribuem mais significativamente para a aprendizagem; se recorria aos materiais que estavam na biblioteca; quais eram os materiais utilizados e como desenvolver o gosto pela leitura nos alunos.

\subsection{Caracterização das colaboradoras da pesquisa}

As colaboradoras da pesquisa foram denominadas de Coordenadora, que é a pessoa que atualmente responde pela biblioteca, pois a escola não tem um funcionário com formação especifica para tal função ${ }^{4}$, e as demais foram denominadas de Professora 1, Professora 2 e

Professora 3, preservando a identidade de cada uma e exercendo os principios éticos da pesquisa.

A Coordenadora tem a faixa etária entre 35 e 40 anos, possui licenciatura em Química e Física, e há cinco anos desenvolve a função de bibliotecária na escola. A Professora 1 também está na faixa etária entre 35 e 40 anos, é formada em Pedagogia e tem duas pós-graduações, uma em Educação Infantil e Séries Inicias e outra em Educação Especial. Atua como professora há cincos anos e leciona na escola pesquisada há três anos.

A Professora 2 possui formação em Pedagogia, tem a faixa etária entre 40 e 50 anos, leciona há 25 anos, e exerce a função de professora nessa escola há dez anos. Já a Professora 3 tem mais de 50 anos, é formada em Pedagogia e tem quatro pós-graduações Latu Sensu: em Metodologia do Ensino Superior, em Libras, em Educação Especial e Inclusiva e nos Anos iniciais do Ensino
Fundamental. Atua como docente há 28 anos e está lecionando na escola há três.

Foram realizadas quatro entrevistas no total. A entrevista com a Coordenadora teve como objetivo compreender o funcionamento da biblioteca da escola e a circulação dos livros entre alunos e professores, enquanto para as

Professoras 1, 2 e $\mathbf{3}$ perguntamos sobre as práticas de leitura desenvolvidas por elas no dia a dia da escola. Assim, a análise dos dados foi organizada em dois momentos, incialmente apresenta-se o resultado da entrevista com a bibliotecária, em seguida, apresenta-se a análise das entrevistas com as três professoras.

\section{Resultados e discussões}

\subsection{A biblioteca da escola e as práticas de leitura no âmbito escolar}

Em relação à biblioteca da escola, conforme informamos, a instituição não possui uma bibliotecária responsável, a Coordenadora acumula essa função. Com o objetivo de conhecer o acervo da escola, indagamos a coordenadora a respeito da existência dos materiais voltados para a alfabetização no 2 . . ano e percebemos em sua fala que na escola há materiais voltados para a alfabetização e também há materiais especificos para o 2. ano.

Sim! Na nossa biblioteca tem os livros de literatura infantil! [...] os livros são separados de acordo com o ano da criança. Lá eu tenho de primeiro ano, do segundo, do terceiro, quarto e quinto (Coordenadora, informação verbal).

[...] eu chamo as crianças, eles vão pegar os livros que são destinados para eles, esses livros de literatura, os livros didáticos já ficam com eles do segundo ano (Coordenadora, informação verbal).

Durante a entrevista a Coordenadora ${ }^{5}$ pontuou que procura desenvolver um trabalho de empréstimo de livros semanalmente com cada turma, ou seja, cada turma tem um dia para escolher o livro na biblioteca. No entanto,

\footnotetext{
4 Para mais informações sobre as histórias das bibliotecas escolas na região sul desse estado, consultar a Tese de Doutoramento da professora Dra. Roseli Maria Rosa de Almeida, intitulada Bibliotecas escolares: história e cultura escolar em Naviraí-MS (1986-2010) defendida pela Universidade Estadual de Maringá (UEM), em 2018.(ALMEIDA, Roseli Maria Rosa de Almeida. Bibliotecas escolares: história e cultura escolar em Navirai/MS (1986-2010) 2018. Tese de conclusão do Doutorado em educação - Universidade Estadual de Maringá - UEM. Maringá. 2018)

5 Depoimento da Coordenadora concedido à pesquisadora Luiara Maria da Cruz na ocasião de elaboração de trabalho de conclusão de curso, na cidade Navirai, MS, Brasil, no dia 18 de abril de 2018.
} 
esse projeto muitas vezes não funciona devido às obrigações que ela, enquanto coordenadora, precisa desenvolver na escola.

Podemos notar que a coordenadora mesmo não possuindo uma formação adequada para exercer o cargo de bibliotecária conhece os livros que a escola possui e procura desenvolver um trabalho contínuo com os alunos e professores. Também notamos que a biblioteca está organizada seguindo a indicação da idade dos alunos, dessa forma, ela "controla" a leitura dos alunos, indicando às crianças os livros das prateleiras separados para cada turma escolar.

Essa classificação de textos para crianças a partir de sua idade é herdeira de uma concepção de leitura e literatura infantil vinculadas a área de Psicologia e divulgadas por Manuel Bergströn Lourenço Filho desde a década de 1940, no Brasil, mais especificamente, a partir do artigo "Como aperfeiçoar a literatura infantil" que teve publicado na Revista Brasileira, em 1943. Sobre a influência de Lourenço Filho na história da literatura infantil brasileira, Bertoletti (2012, p. 106-107) destaca:

[...] Lourenço Filho traça uma ordenação geral dos livros de literatura infantil e juvenil, de modo a enquadrar a produção existente, com o objetivo de satisfazer as necessidades de "ordem prática", consciente do "valor aproximativo" que esse enquadramento resulta, e estabelece um critério básico: o das "idades infantis" (considerando também os "pré-adolescentes e adolescentes") para essa ordenação. Assim, os aspectos constitutivos do livro são critérios relevantes aos livros infantis e juvenis, desde que adequados à idade do leitor, pois o que regula essa ordenação são, num primeiro plano, concepções psicológicas e educacionais. Esse critério passa a servir de base para classificação do gênero até os dias atuais

Conforme Bertoletti (2012) menciona em sua tese de doutoramento, os critérios de escolha por idade de obras destinadas para a infância passam a ser o principal item a ser observado na compra e venda de títulos. Esse critério vinculado a uma herança psicológica (e não literária) vem sendo perpetuado pelas editoras ainda no presente e está no senso comum de professores e bibliotecários que buscam seguir tais prescrições.

A coordenadora ainda pontuou que na biblioteca não existem apenas materiais voltados para a alfabetização da língua portuguesa, mas que também é possivel encontrar materiais para a alfabetização matemática, como destaca em uma de suas falas:

[...] nós temos também os jogos, jogos pedagógicos de matemática, de gramática, de interpretação que são dominós... são vários os tipos de jogos educativos que tem, que nós temos destinados a essa série do segundo ano [...] jogos de fração, sólidos geométricos, bem assim, ilustrativos que é para essa parte de alfabetização das crianças, chamar a atenção, o material dourado que é muito utilizado na aprendizagem de matemática (Coordenadora, informação verbal).

Quando perguntada se os materiais da biblioteca estavam disponiveis para uso dos professores, a coordenadora nos responde que sim.

\begin{abstract}
Eles estão disponíveis sim. Ficam lá na nossa minibiblioteca aqui da escola e toda vez que o professor precisa, ele vem me procura ou procura outro coordenador da escola e pega esse material para usar na sala com as crianças (Coordenadora, informação verbal)
\end{abstract}

A coordenadora explica que esses materiais são procurados com muita frequência pelos professores: "[...] praticamente todo dia tem um ou outro professor vindo aqui e pede esse material, porque ajuda muito na parte pedagógica, porque é uma didática diferente".(Coordenadora, informação verbal) Em um momento a coordenadora comentou que os professores ao fazerem os planejamentos das aulas já citam o material que vão utilizar, principalmente quanto aos jogos ou livros de leitura, porque é uma forma mais lúdica de atrair o aluno para a aula, fazendo com que ele participe e interaja com os demais colegas e com o professor, como é possivel perceber na seguinte resposta:

\begin{abstract}
Por que eles pegam os livros com as histórias menores e ali trabalha interpretação, trabalha teatro, trabalha a música, trabalha muita coisa assim, né! Pintura. Então é um caminho aberto essa leitura desses livros pelas crianças, então eles são bastantes utilizados (Coordenadora, informação verbal).
\end{abstract}

As respostas da Coordenadora são sempre muito positivas em relação aos empréstimos de livros para o uso dos professores e comenta 
que mesmo sem ter um espaço adequado para armazenar esses materiais, eles sempre são procurados por professores. A escola possui uma sala que foi incialmente destinada à biblioteca e deveria atender não só a escola, mas também a comunidade ao redor da instituição, no entanto, nunca foi utilizada devido à defasagem de profissional qualificado na área e pela falta de acervo necessário para "preencher" uma biblioteca.

A biblioteca foi construída com verba pública e não era para atendimento somente da escola! Essa biblioteca inclusive tem uma entrada separada que é, seria para toda comunidade que se interessasse. Então, ali teria uma pessoa para trabalhar, um bibliotecário né, disponivel só ali naquele espaço. Mas, até hoje, já tem vários anos, não sei precisamente quantos que ela está construída e ela não funciona para o que foi feito. (Coordenadora, informação verbal)

Na verdade, deveria ter uma pessoa para trabalhar só essa questão de livros, né... de controle, de tombamento, tudo isso tinha que ter. Porque meu tempo é escasso, porque a gente tem um monte de outras funções para fazer, porque eu sou coordenadora da escola, então não tem como a gente atender. (Coordenadora, informação verbal)

Podemos perceber que a escola necessita de uma pessoa capacitada para atuar na biblioteca, uma vez que a coordenadora já exerce outras funções. No entanto, em muitas escolas há a precariedade de um bibliotecário especializado para exercer essa função e por esse motivo funcionários de diversas áreas atuam como tal, como aponta Corrêa, Oliveira e Bourscheid (2002, p. 2):

Além das já conhecidas precariedades em termos de espaço físico e acervo, muitas delas "funcionam" com a presença de profissionais de diversas áreas, principalmente da educação, como professores e funcionários de diversos departamentos da escola, geralmente readaptados e aguardando a aposentadoria (CORREA; OLIVEIRA; BOURSCHEID, 2002, p. 2).

Válio (1990, p. 7) argumenta que "[...] se a biblioteca tem a função de contribuir para a formação de cidadãos, o papel do bibliotecário seria de facilitar tal aprendizagem para cada estudante". Silva (2011, p. 6) ressalta que "[...] a década de 1930 foi crucial para pensar e propor ações no âmbito da biblioteca escolar", pois até então as bibliotecas estavam relacionadas com à igreja. Somente na década de 1970 começa a ter seus traços que conhecemos hoje. Assim, podemos perceber que a biblioteca escolar está relacionada com toda a atividade da escola, e o bibliotecário desempenha o trabalho de apoio e complemento para os professores que o procuram.

Com base nas palavras de Válio (1990, p. 8) “[...] o bibliotecário é um professor cuja disciplina é ensinar a aprender". Dessa forma, ele possui um papel fundamental na formação de um leitor desde pequeno, pois incentiva a leitura literária com um projeto pessoal de formação de leitores que desenvolve na escola.

Nesse contexto, os professores são incentivados pela coordenação a utilizarem os recursos pedagógicos que estão na biblioteca como jogos e outros materiais no processo de alfabetização aos alunos. De acordo com a coordenadora, os professores buscam livros "curtos" para atividades de alfabetização em sala de aula a fim de proporcionar uma leitura que não seja apenas do livro didático.

A seguir apresentamos os resultados das entrevistas com as três professoras.

\subsection{Práticas de leitura realizadas pelas professoras alfabetizadoras}

Em entrevista com as Professoras. perguntamos quais eram os motivos que levavam a escola a obter o maior indice do Ideb na cidade e região, todas elas responderam que os motivos estavam relacionados ao trabalho em equipe, ao apoio pedagógico que a escola oferece e à prática de estudos e simulados feitos com os alunos. A

Professora $1^{6}$ respondeu da seguinte maneira:

Olha, um dos principais motivos que eu acho [...] é um trabalho em equipe, em conjunto, primeira coisa é isso dai que não depende somente de quem está na alfabetização. Depende de todos que estão envolvidos no processo, você entendeu? Esse é um dos fatores que eu acho principal, o envolvimento de todos, não só mes-

\footnotetext{
6 Depoimento da Professora 1 concedido à pesquisadora Luiara Maria da Cruz na ocasião de elaboração de trabalho de conclusão de curso, na cidade Naviraí, MS, Brasil, no dia 18 de abril de 2018.
} 
mo do professor que está ali na alfabetização (Professora 1, informação verbal).

Nesse mesmo sentido, a Professora $2^{7}$ destacou que recebe muito apoio da coordenação e para ela, o motivo pelo qual a escola atingiu êxito na nota do Ideb deve-se a esse apoio.

O que difere para mim aqui é a maneira como eu sou tratada, eu fico muito à vontade para eu trabalhar, porque um professor pode ter a segurança que for na sala de aula, mas se ele não tiver uma equipe pedagógica boa, que te assessora bem e que confia no seu trabalho, te ajuda nas horas que você precisa nos momentos de fraqueza, ou até de dizer: eu não sei, e você ter aquela equipe para te ajudar, te apoiar (Professora 2, informação verbal).

Além do apoio pedagógico, a Professora 2 explica como realiza suas atividades de leitura em sala de aula.

Então a gente em cima disso trabalha teatro, dramatização na sala de aula, imitação, canto, né! Eu tenho um karaokê na minha casa, eu trago com microfone e tudo e eles cantam musiquinhas [...] poesia, trava língua, parlenda. Então tudo isso nós já trabalhamos no segundo ano, e isso já adianta muito para um terceiro, quarto ano, o que dirá um quinto em diante (Professora 2, informação verbal)

A Professora 2 realiza seu trabalho pautado nos gêneros textuais, com a produção coletiva de textos pelos próprios alunos, com músicas, histórias do folclore e teatro. Já na opinião da Professora $3^{8}$, a escola obteve esse indice decorrente dos trabalhos com estudos e simulados: "Trabalhando muito com estudos, simulados"(Professora 3, informação verbal) Esses simulados se referem a questões semelhantes às da provinha Brasil e as Avaliações Nacionais da Alfabetização (ANA) que a escola toma como base para aplicar aos alunos.

Após obter essas respostas, podemos perceber que as professoras atribuem o "sucesso" da escola a diferentes fatores, a Professora 1 atribui ao apoio pedagógico e ao trabalho em equipe, a Professora 2 ao trabalho com diferentes gêneros textuais realizado em sala, e a Professora 3 à prática de estudos simulados. Esses dados demonstram certa contradição, mas também evidenciam a complexidade de fatores que envolvem os bons resultados na aprendizagem da leitura. Observamos que não há uma prática especifica e embora estejam trabalhando com turmas semelhantes, cada professora atribui o sucesso da alfabetização a fatores diferentes.

Buscamos conhecer quais ações eram desenvolvidas com os alunos para promover a aquisição da leitura no $2^{\circ}$. ano do ensino fundamental, as Professoras 2 e 3 tiveram o mesmo posicionamento e enfatizaram que no processo de alfabetização priorizavam a leitura de textos. A Professora 2 pede livros para os pais:

Então, eles fazem a doação eu guardo no armário e todos os dias eu coloco uma mesinha lá no fundo da sala. E quando eu vou dar outra matéria [...], pode ser em qualquer aula, terminou uma atividade enquanto os outros não terminam [...] eu deixo pegar um livrinho e ir lendo. Então eu sempre trabalhei assim, e deu certo e está dando certo (Professora 2, informação verbal).

Essa professora menciona o projeto que a coordenadora da escola oferece para as crianças, como podemos perceber na seguinte fala:

[...] a coordenação dá [livros] uma vez por semana, ela vai lá e marca o nome das crianças, que levam para casa e pegam outro no lugar. Então muitas vezes, eu pego esse livro que levou para casa para saber se eles estão lendo ou não e eu faço um círculo atrás da sala, na grama (Professora 2, informação verbal).

A Professora 3 ressaltou o trabalho desenvolvido pela coordenadora e a relação entre o trabalho das professoras e da biblioteca: "Da leitura trabalhando o projeto de leitura. Os alunos levam livros toda semana e trazem para trocar (Professora 3, informação verbal). A Professora 1 não explicou como faz o trabalho com a leitura, mas frisou a importância da familia nesse processo, destacando que a familia precisa estar presente auxiliando nas tarefas que são

\footnotetext{
Depoimento da Professora 2 concedido à pesquisadora Luiara Maria da Cruz na ocasião de elaboração de trabalho de conclusão de curso, na cidade Naviraí, MS, Brasil, no dia 18 de abril de 2018.

8 Depoimento da Professora 3 concedido a pesquisadora Luiara Maria da Cruz na ocasião de elaboração de trabalho de conclusão de curso, na cidade Naviraí, MS, Brasil, no dia 18 de abril de 2018.
} 
adotadas na rotina de trabalho dessa professora.

Olha, diariamente o que eu trabalho assim é constante. Na alfabetização é família e a escola, aqueles alunos que não têm o desenvolvimento é porque não têm o acompanhamento da familia. Então assim, a familia é um dos pontos chave para acontecer a alfabetização do aluno, entendeu? Então, uma coisa que é sempre desenvolvido durante o ano, a participação da tarefa, todos os dias, sempre tem tarefa todos os dias, só na sexta que eu não costumo enviar tarefa (Professora 1, informação verbal).

De forma geral, em relação às três professoras, notamos que uma estratégia para o desenvolvimento da leitura é envolver os pais na leitura individual de seus filhos, seja por meio dos livros enviados para leitura em casa, seja pela tarefa de todos os dias. Os professores trabalham durante as aulas, mas organizam-se para compartilhar com os pais essa responsabilidade: "Com os livros que levam para casa, ajuda da familia. Os projetos que são desenvolvidos durante o ano" (Professora 3, informação verbal).

Também buscamos compreender as práticas que na opinião delas, geravam maior resultado na aprendizagem da leitura. A Professora 1 comentou:

É as leituras, esses contos mais clássicos. Que são as historinhas mais conhecidas por eles, essas parlendas, é, as fábulas, esse grande mix do folclore brasileiro que a gente tem né. Eles amam isso daí, eles amam! [...]

Então, é assim. É uma coisa que você tem que estar em contato direto com eles, tanto para ajudar na leitura para eles aprender, ter esse gosto de aprender a ler, como na questão da escrita também, que através disto dai você vai desenvolver a escrita com base nisso, né. Você aproveita desse recurso e trabalha já a escrita com eles (Professora 1, informação verbal).

\section{Embora na citação acima a Professora 1 mencione} o trabalho com gêneros textuais, ela não assume nenhum posicionamento teórico a esse respeito, e considera o seu "método de ensino complexo", conforme observa-se no fragmento abaixo:

[...] eu até falo, ele é um pouco complexo [método de ensino]. A alfabetização vai depender muito do diagnóstico que você viu no seu aluno que você vai dar o seu recurso para trabalhar com ele. Porque assim, né uma sala de alfabetização nem sempre o que eu trabalho uma atividade com uma criança a outra está no nivel que aquela se encontra, então assim, eu trabatho com aquilo que vai dar certo com o perfil de cada aluno, ou de forma silábica, ou de forma fazendo alfabetizar letrando, ou cantando, vai depender da hipótese, do perfil de cada aluno (Professora 1, informação verbal).

Pela resposta da professora percebemos que sua prática está relacionada com o ecletismo teórico, pois ela não desenvolve um método específico em sala de aula. De acordo com Mortatti (2011, p. 7) "[...] o que vem predominando hoje em nosso país é um ecletismo, ou seja, uma 'mescla', nos níveis teórico-conceitual, processual e procedimental, de diferentes propostas de ensino derivadas de diferentes epistemologias", onde cada professor desenvolve a sua função de ensinar por meio de vários métodos.

Mortatti (2011, p. 10) salienta que os professores organizam diversas "[...] atividades especificas para 'propiciar' a 'passagem' para o nivel seguinte de aquisição da escrita", muitas vezes, sem saber que utilizaram palavras decorrentes de um conceito e atividades decorrentes de outro totalmente diferente.

Com as respostas obtidas, podemos entender que todas as professoras fazem uso de diferentes tipos de recursos e abordagens teóricas para conduzir o trabalho. No entanto, as professoras não expuseram abertamente como realizam a rotina de alfabetização com as crianças, tão pouco se posicionaram teoricamente.

É possivel notar que não existe uma proposta de alfabetização específica sendo exercida pela escola, cada professor trabalha de acordo com suas experiências anteriores e encontram na direção e coordenação o apoio que precisa, sem a imposição de uma definição de modelo de trabalho pedagógico especifico. Também percebemos que é o trabalho da coordenadora que articula todas as práticas das professoras em torno da leitura literária, como uma "política escolar" de formação de leitores naquele ambiente.

Por meio desses relatos, notamos que todas as professoras deixam explícito o contato que há com a biblioteca da escola, elas veem esse espaço como um ponto positivo para a escola. A organização com os professores nos empréstimos 
de livros e o projeto que a coordenadora vem realizando com os alunos semanalmente tem gerado um vínculo de cooperação na escola. Desse modo, a formação de um aluno que tenha gosto pela leitura é um dos maiores objetivos da escola, uma vez que, é por meio da leitura que o aluno conseguirá atingir um maior nível de conhecimento. "Para o professor, fica a missão de estimular constantemente e ser exemplo pelo interesse na leitura" (GOMES, 2011, p. 2).

Geraldi (1994, p. 60) reforça a ideia de que a aprendizagem da leitura deve ser trabalhada de acordo com "[...] textos curtos como contos, crônicas, reportagens, lendas, notícias de jornais, editoriais, etc., e a formação do gosto por meio de narrativas longas caracterizadas como romances e novelas". Dessa forma, o aluno perceberá que a leitura além de ser uma distração, amplia seus conhecimentos e o torna cada vez mais significativos. (GERALDI, 1994).

Nessa perspectiva, Mortatti (2001, p. 136) ressalta ainda que é possivel "[...] aprender a ler e a gostar de ler textos de qualidade literária e pode-se formar o gosto pela leitura". Nesse sentido, "[...] a formação de um quadro vivo de leitores não se dá no vazio ou apenas por acaso" (PERROTTI, 1990, p. 63), é necessário que o aluno perceba quão prazeroso é o ato de ler, para que ele saiba que a leitura lhe trará possibilidades de enriquecer seus conhecimentos.

De acordo com Perrotti (1990, p. 66), "la] escola é um espaço onde se deve, de forma planejada, independentemente das condições gerais do ensino, atrair, ganhar, conquistar leitores". Com isso, podese concluir que o professor é indispensável nesse processo, pois através de suas ações desenvolvidas em sala de aula é que serão desenvolvidos o interesse e o hábito de leitura nos alunos.

Podemos dizer que os resultados desta pesquisa foram surpreendentes por diferentes motivos: pela falta de coesão nos trabalhos das professoras que lecionam para crianças na mesma faixa etária; pela ausência de uma única proposta de alfabetização ou de método de ensino explicitamente assumido por elas; e pelo modo como a leitura literária tem sido capaz de trazer unidade, satisfação e resultados reconhecidamente satisfatórios para a escola.

\section{Considerações finais}

O período de alfabetização é de suma importância na vida do aluno, no entanto, esse processo exige dedicação, competência e comprometimento dos professores e da escola para desenvolver atividades, projetos e outras ações que permitam que o aluno tenha êxito em sua aprendizagem.

A escola investigada procura desenvolver a alfabetização por meio de projetos de leitura com os alunos, articulados especificamente pela figura da coordenadora que exerce a função de bibliotecária. Não observamos muitas atividades lúdicas com jogos, músicas, teatro entre outros, mas podemos observar a preocupação e o comprometimento da instituição com a aprendizagem da leitura, da escrita e do cálculo. O ensino da leitura desenvolvido pela escola ocorre em relação à frequência com que os alunos buscam livros na biblioteca, mas, não há um trabalho sistemático de cobrança sobre essa leitura, eles apenas levam os livros para ler em casa, nos fazendo lembrar do professor João Wanderley Geraldi (1994) quando afirma que a "formação do gosto" vem por meio da leitura de narrativas longas".

No acervo da escola existem materiais que são voltados à alfabetização para as turmas de $2^{\circ}$. ano e são disponibilizados a qualquer momento aos professores que por sua vez utilizam com frequência para desenvolver suas práticas dentro e fora da sala de aula. As professoras também possuem o seu próprio material de apoio para utilizar nos planejamentos e com a turma. Nesse sentido, as docentes procuram envolver os pais e a coordenação nas atividades realizadas em sala de aula, pois tem sido o diferencial na aprendizagem desses alunos.

Um dado importante a ser destacado é que a pesquisa foi realizada em uma escola estadual de ensino fundamental que está situada no centro da cidade, em uma região favorecida economicamente. De acordo com Ribeiro, Almeida e Gomes (2006) no artigo "Conhecimentos prévios, 
sucesso escolar e trajetórias de aprendizagem:

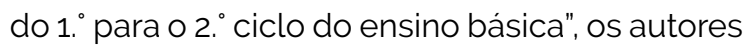
indicam que alunos que possuem estilos de vida melhor, acesso aos bens culturais, ao lazer, serviços, e o fato de estarem situados em lugares economicamente favorecidos, apresentam uma melhor aprendizagem.

Sob essa ótica, Saavedra (2001) discorre confirmando que o insucesso dos alunos que se encontram em classes sociais menos favorecidas é maior do que aqueles que frequentam a escola do centro. Saavedra (2001, p. 68) enfatiza que o insucesso e os níveis econômicos influenciam na aprendizagem do aluno.

A associação entre o insucesso escolar e os niveis econômicos mais desfavorecidos não é novidade. É geralmente reconhecido que os alunos das classes sociais mais desfavorecidas têm uma atitude negativa face à escola, pouca motivação e dificuldade em realizar com sucesso as tarefas nela propostas [...] a classe social é frequentemente considerada como podendo criar situações de risco, quando é baixa, porque grande parte das crianças provenientes de meios socioeconômicos e culturais desfavorecidos têm ambientes familiares intelectualmente pouco estimulantes (SAAVEDRA, 2001, p. 68).

Essa é a realidade da escola onde foi desenvolvida a pesquisa, pois há alunos com melhores condições de vida que em escolas localizadas em outros bairros da cidade. É possivel perceber como a classe social influencia a aprendizagem dos alunos, pois é notório a diferença entre os dois extremos geográficos em um mesmo municipio. Percebe-se que os responsáveis estão presentes quando o assunto é contribuir com a aprendizagem dos filhos, auxiliando-os com as tarefas e leituras para casa.

Além do mais, as professoras procuram desenvolver atividades como produção de textos feitas pelos próprios alunos, confecção do alfabeto, entre outros. Com isso, a escola deposita total confiança no trabalho desenvolvido pelas professoras, seja por simulados, gêneros textuais ou ensino "tradicional".

De certa forma, os relatos das professoras fizeram-nos recordar do projeto de extensão desenvolvido em alfabetização e letramento, porque houve a possibilidade de colocar em prática aquilo que é visto na universidade e comprovar que o resultado final tem sido positivo. Do mesmo modo que as professoras acreditam em cada um de seus alunos, no projeto foi exercitado essa qualidade em cada um dos integrantes: acreditar que o aluno é capaz de aprender.

Conclui-se que o ensino da leitura é um trabalho árduo e prazeroso, mas que se deve ser trabalhado, dia após dia, durante o ano letivo. Só é possivel adquirir o gosto pela leitura, lendo. Por isso, é necessário que haja professores comprometidos com a educação e que tenham prazer em ensinar. Também se observou que uma gestão pedagógica que seja articuladora das práticas docentes é fundamental nesse ambiente de trabalho, pois foram múltiplas as práticas de leitura realizadas por essas professoras alfabetizadoras. Diante disso, nos perguntamos: como se ensina a ler? Talvez, um caminho seja acreditar no poder da literatura (CANDIDO, 1976).

\section{Referências}

ALMEIDA, Roseli Maria Rosa de. Bibliotecas escolares: história e cultura escolar em Naviraí/MS (19862010). 250f. Tese (Doutorado em Educação) - Universidade Estadual de Maringá. Maringá, 2017.

BERTOLETTI, Estela Natalina Mantovani. Lourenço Filho e literatura infantil e juvenil. São Paulo: Editora Unesp, 2012.

BRASIL. Instituto Nacional de Estudos e Pesquisas Educacionais Anísio Teixeira - INEP. Índice de Desenvolvimento da Educação Básica - IDEB. (2015). Brasilia: INEP, 2015. Disponivel em: http://ideb.inep. gov.br/resultado/. Acesso em: 02 nov. 2018.

BRASIL. Ministério da Educação - MEC. Ciclo de Alfabetização deve prosseguir sem interrupção Brasilia, 2010. Disponivel em: http://portal.mec.gov. br/ultimas-noticias/211-218175739/16166-ciclo-de-alfabetizacao-deve-prosseguir-sem-interrupcao. Acesso em: 08 dez. 2018.

BRUNERI, Bruno Marini. Alfabetização e letramento as concepções dos acadêmicos de licenciatura da UFMS/campus do Pantanal. 2013. Disponivel em: http://www.fe.ufg.br/nedesc/cmv/controle/DocumentoControle.php?oper=download\&cod $=1690$. Acesso em: 1.out. 2017.

CANDIDO, Antonio. A literatura e a formação do homem. Remate de Males, Campinas, SP, dez. 2012. ISSN 2316-5758. Disponivel em: https://periodicos. sbu.unicamp.br/ojs/index.php/remate/article/ view/8635992. Acesso em: 23 abr. 2019. 
CARVALHO, Maria Angélica Freire de; MENDONÇA, Rosa Helena (org.). Práticas de leitura e escrita. Brasília: Ministério da Educação, 2006. Disponivel em: http:// WWW.atividadeseducativas.com.br/atividades/5212_ salto_ple.pdf\#page=12. Acesso em: 1 out. 2017.

CORRÊA, Elisa Cristina Delfini; OLIVEIRA, Karina Costa de; BOURSCHEID, Laura da Rosa et al. Bibliotecário escolar: um educador? Revista ACB: Biblioteconomia em Santa Catarina, Florianópolis, n. 1, v. 7. p. 107123, 2002. Disponivel em: https://revista.acbsc.org.br/ racb/article/view/379/459. Acesso em: 31 jul. 2018.

FREIRE, Paulo. Carta de Paulo Freire aos professores: ensinar, aprender - leitura do mundo, leitura da palavra. Estudos avançados, São Paulo, v. 15. n. 42, maio/ago.2001. Disponivel em: http://scielo. br/scielo.php?pid=S0103-40142001000200013\&script_arttext. Acesso em: 10 out. 2017. https://doi. org/10.1590/S0103-40142001000200013

GERALDI, João Wanderley (org.). O texto na sala de aula. Campinas: UNICAMP; Cascavel: Assoeste, 1984.

GOMES, Maria Lúcia de Castro. Metodologia do ensino da lingua portuguesa. 2, ed. rev. e ampl. Curitiba: Ibpex, 2011.

JESUS, Davi Brandão de. A importância da Leitura dos Livros Paradidáticps nas Séries Iniciais do Ensino Fundamental. Blog Pedagogia ao pé da letra, 2006. Disponivel em: https://pedagogiaaopedaletra. com/a-importancia-da-Leitura-dos-livros-paradidaticos-nas-series-iniciais-do-ensino-fundamental/. Acesso em: 11 out. 2017.

MARUNY, Curto Lluis; MORILLO, Maribel Ministra; TEIXIDÓ, Manuel Miralles. Escrever e ler: Como as crianças aprendem e como o professor pode ensiná-las a escrever e a ler. Trad. Ernani Rosa. Porto Alegre: Artmed, 2000.

MACIEL, Francisca Izabel Pereira; MONTEIRO, Sara Mourão; BAPTISTA, Mônica Correia (org.). A criança de 6 anos, a linguagem escrita e o ensino fundamental de nove anos: orientações para o trabalho com a linguagem escrita em turmas de crianças de seis anos de idade. Belo Horizonte: UFMG/FaE/ CEALE, 2009. Disponivel em: http://portaldoprofessor.mec.gov.br/storage/materiais/0000012182.pdf. Acesso em: 1.out. 2017

MONTEIRO, Sara Mourão; BAPTISTA, Mônica Correia O Ensino e a Aprendizagem da Linguagem escrita em classes do primeiro ano do Ensino Fundamental. Brasilia: Ministério da Educação, 2009. (Salto para o futuro, Ano XIX, n. 12). Disponivel em: http:// portaldoprofessor.mec.gov.br/storage/materiais/0000012182.pdf. Acesso em: 21 nov. 2018.

MORTATTI, Maria do Rosário Longo. Função social da escola: aspectos históricos e metodológicos da alfabetização. In: ENCONTRO DE PESQUISA EM EDUCAÇÃO, 5., XVII Semana de Pedagogia da UEM/ II Jornada de Gestão Escolar, 5., 2010, Maringá. Anais[...] Maringá: UEM, 2010.

MORTATTI, Maria do Rosário Longo. Leitura, literatura e escola: sobre a formação do gosto. 2. ed. São Paulo: Martins Fontes, 2011.
PERROTTI, Edmir. Confinamento cultura, infância e leitura. São Paulo: Summus, 1990. (Novas buscas em educação; v. 38)

REUEN, Adriana Regina Feltrin. Práticas pedagógicas que estimulam a leitura. In: PARANÁ. O professor PDE e os desafios da escola pública Paranaense Volume I. Curitiba: Governo do estado do Paraná, 2007. Disponivel em: http://www.diaadiaeducacao. pr.gov.br/portals/pde/arquivos/390-4.pdf. Acesso em: 1 out. 2017.

RIBEIRO, Elisa Antonia. A perspectiva da entrevista na investigação qualitativa. Evidência: olhares e pesquisas em saberes educacionais, Araxá, v. 4. n. 4, p.129-148, 2008. Disponivel em: http://www. uniaraxa.edu.br/ojs/index.php/evidencia/article/ viewFile/328/310. Acesso em: 18 jul. 2018

RIBEIRO, Iolanda S.: ALMEIDA, Leandro S.; GOMES Carlos. Conhecimentos prévios, sucesso escolar e trajectórias de aprendizagem: do $1^{\circ}$ para o $2^{\circ}$ ciclo do ensino básico. Aval. psicol., Porto Alegre, v. 5 n. 2, p. 127-133, dez. 2006. Disponivel em: http:// pepsic.bvsalud.org/scielo.php?script=sci_arttext\&pid=S1677-04712006000200002\&lng=pt\&nrm=iso Acesso em: 20 nov. 2018.

ROSA, Maria Virgínia de Figueiredo Pereira do Couto: ARNOLDI, Marlene Aparecida Gonzalez Colombo. A entrevista na Pesquisa Qualitativa: Mecanismos para validação dos resultados. Belo Horizonte: Autêntica, 2017. Disponivel em: https://books.google. com.br/books? id = J8MpDWAAQBAJ\&printsec $=$ fron tcover\&hl=pt-BR\&source=gbs_ge_summary_r\&ca$\mathrm{d}=0 \# \mathrm{v}=$ onepage \&q=ano\%20 de\%20publicacao\%20 \&f=false. Acesso em: 18 jul. 2018.

SAAVEDRA, Luísa. Sucesso/insucesso escolar: A importância do nível socioeconómico e do género. Psicologia, Lisboa, v. 15, n. 1, p. 67-92, jan. 2001. Disponivel em: http://www. scielo.mec.pt/scielo.php?script=sci_arttext\&pi$\mathrm{d}=\mathrm{S} 0874-20492001000100004 \& \mathrm{lng}=\mathrm{pt} \& \mathrm{nrm}=\mathrm{iso}$. Acesso em: 20 nov. 2018. https://doi.org/10.17575/ rpsicol.v15i1.491.

SEAL, Ana Gabriela de Souza; SILVA, Alexsandro da. O ensino do Sistema de Escrita Alfabética no segundo ano do ciclo da alfabetização. In: BRASIL. Ministério da Educação. Programa Nacional pela Alfabetização na Idade Certa - PNAIC. Unidade 3. Brasília. 2012. Disponivel em: http://www.pomerode.sc.gov.br/ arquivos/SED/ano2/unidade_03_ano_02_laranja(testes_figuras)(07_11_2012).pdf. Acesso em: 6 ago. 2018.

SILVA, Jonathas Luiz Carvalho. Perspectivas históricas da biblioteca escolar no Brasil: análise da Lei 12.244/10 que dispõe sobre a universalização das bibliotecas escolares. Revista ACB: Biblioteconomia em Santa Catarina, Florianópolis. v.16, n. 2, 2011. Disponivel em https://revista.acbsc.org.br/racb/article/ view/797. Acesso em: 29 jul. 2018.

SOARES, Magda. Alfabetização e Letramento: caminhos e descaminhos. Pátio: Revista Pedagógica, Porto Alegre, ano 7, n. 29, p. 96-100, fev./abr. 2004. Disponivel em: https://acervodigital.unesp.br/bitstream/123456789/40142/1/01d16to7.pdf. Acesso em: 1.out. 2017 
VÁLIO, Else Benetti Marques. Biblioteca Escolar: uma visão histórica. Trans-in-formação, Campinas, v. 2, n. 1, jan./abr.1990. Disponivel em: http://periodicos. puc-campinas.edu.br/seer/index.php/transinfo/article/viewFile/1670/1641. Acesso em: 30 jul. 2018.

TEBEROSKY, Ana, COLOMER, Teresa. Aprender a Ler e a Escrever: uma proposta construtivista. Porto Alegre: Artmed. 2002.

\section{Luiara Maria da Cruz}

Graduada em Pedagogia pela Universidade Federal de Mato Grosso do Sul (UFMS), campus de Navirai (2015-2018). Pós-Graduada em Especialização em Educação Especial e Inclusiva com Ênfase em Deficiências. (Pós Latu Sensus) (2019). Atua como professora da Educação Básica do Estado de Mato Grosso do Sul em Naviraí. Integrante do grupo de pesquisa GEPETE - Grupo de Estudos e Pesquisas em práticas Educativa e Tecnologia Educacional.

\section{Vivianny Bessão de Assis}

Professora Adjunta do curso de Pedagogia da Fundação Universidade Federal de Mato Grosso do Sul (Campus de Navirai-MS). Doutora em Educação pela Faculdade de Filosofia e Ciências (FFC) da Universidade Estadual Paulista (UNESP), campus de Marilia (SP) (2016) (Bolsa CAPES). Mestre em Letras pela Universidade Federal de Mato Grosso do Sul (UFMS), campus de Três Lagoas (MS) (2009) (Bolsa CAPES). Graduada em Pedagogia pela Universidade Federal de Mato Grosso do Sul (UFMS), campus de Três Lagoas (MS).

\section{Endereço para correspondência}

Luiara Maria da Cruz/Vivianny Bessão de Assis

MS-141, 04

79950-00

Naviraí, MS, Brasil 